\title{
Topic Study Group No. 36: Task Design, Analysis and Learning Environments Programme Summary
}

\author{
Jere Confrey, Jiansheng Bao, Anne Watson, Jonei Barbosa \\ and Helmut Linneweber-Lammerskitten
}

\section{The Programme}

Our TSG36 program included contributions from continents around the world: Africa, Asia, Europe, North and South America, and Oceania. Plenaries were presented by Anne Watson (UK), Koeno Gravemeijer (NED), Kazuhiko Nunokawa (JP), Berta Barquero, Ioannis Papadopoulos, Mario Barajas, and Chronis Kynigos (SP, GR) Angelika Kulberg (SWE), and Celia Hoyles and Richard Noss (UK). Twenty six papers and thirteen posters were presented. Confrey (USA) authored a closing summary. The presentations are listed below (posters omitted due to space constraints); the text references these contributions.

Topic Study Group 36's presentation began with the framework proposed by a prior ICME Topic Study Group (Watson) organized into the categories (or parameters) of Theory, Intentions, Likely Activity and Implementation. Over the course of the conference, additional components of a framework for TSG 36 emerged around (a) tasks, (b) learning environments, and (c) theory. Within the component of tasks, the topics addressed included how tasks are sequenced and structured (Gravemeijer, Brady et al., Goa et al.) what representations and tools were used in tasks (Thiel-Schneider, Johnson), what kinds of activities and actions

Co-chairs: Jere Confrey, Jiansheng Bao.

Team members: Anne Watson, Jonei Barbosa, Helmut Linneweber-Lammerskitten.

J. Confrey $(\bowtie)$

North Carolina State University, Raleigh, NC, USA

e-mail: jconfre@ncsu.edu; jere_confrey@ncsu.edu

J. Bao

East China Normal University, Shanghai, China

e-mail: jsbao@math.ecnu.edu.cn

(C) The Author(s) 2017

G. Kaiser (ed.), Proceedings of the 13th International Congress on Mathematical

Education, ICME-13 Monographs, DOI 10.1007/978-3-319-62597-3_63 
were taken (Palatnik, Schäfer \& Linneweber-Lammerskitten), the meaning of cases and classifications (Kulberg) and their effects on instruction and the type of feedback provided. Within the topic of learning environments, topics included student-to-student and student-to-teacher interactions (Mok et al.), curricular approaches (Goa et al.), assessment (Sharma et al.) and teacher knowledge and teacher roles in instruction (Dietiker et al., Lee) A variety of views of the student and learning were addressed. The use of theories in the presentations ranged from "grand theories" such as Realistic Maths (Gravemeijer), Socio-Epistemological Theory (Montiel et al.), Socio-Constructivism and Constructionism (Hoyles \& Noss, Barquero et al.), and intermediate or "bridging theories" such as local instructional theories (Gravemeijer), task variations (Kulberg) and exemplifying (Kim \& Park), problem solving approaches (Nunokawa), project-based instruction (Barquero et al.), learning trajectories (Confrey), and place-based design (Zender \& Ludwig). Discussions indicated that task design work is evolving towards ever more careful description of local instructional theories to ensure that grand theories are held accountable to their impact on the design and research. Attention to addressing how tasks reside within sequences (Brady et al.), hierarchies (Tan et al.), frameworks of mathematical relations (Gravemeijer), and cases (Kulberg) arose across presentations.

The TSG also had a strong and consistent focus on both the design and research processes. This focus drew attention to iterative and agile design (Confrey), emergent modeling (Gravemeijer), shifting communities of interest (Barquero et al.), mind maps (Barquero et al.), progress maps (Isidro Camac et al.), navigation (Zander et al.), pre- and post-design (Kulberg), studies of classroom practices and implementation (Johnson), clinical interviewing (Tan et al.), and crowd-sourcing (Zander et al.).

From the talks and presentations as a whole. four themes emerged that bear further examination and development. The TSG36 members varied in the extent to which they acknowledged an important role for (1) re-envisioning the purpose and characterizations of doing mathematics, (2) considering how to design from the perspective of the student, (3) articulating, sharing, and strengthening the foundation of professional knowledge, and (4) articulating a role for learning systems in providing feedback, diagnostic/formative assessment, and supporting iterative design.

Attempts to re-envision the purpose and characterization of doing math came from a variety of presentations. Hoyles and Noss stated "in technology-enhanced mathematics classrooms, the use of digital tools can disrupt routine practices in a transformative sense, and ensuing breakdowns can promote further reflection and thinking again." Olsher et al. described how "The design principles of this game setting provide a unique and innovative implementation to the use of online dynamic figures in a game setting that is strongly rooted in meaningful mathematical work of students." Barquero et al. also emphasized in their joint enterprise 
of building an e-book that "... also, mathematical modelling was considered as a crucial approach to cope with most of the extra-mathematical questions, and progressively build up mathematical models to study the complexity of the questions posed along the unit, linking and articulating the models appearing at each step."

Consideration of how to design from the perspective of the student arose repeatedly in presentations emphasizing the need to connect to student experiences (Johnson, Nunokawa) and as relevant to their current and evolving identities. For instance, Nunokawa addressed how students learn to appreciate what kind of advantages the new ideas have over the previous ones. The importance of leveraging multiple representations (Johnson) arose along with articulating different student models (Kraemer et al., Rojas et al.). Wilkes described how sophisticated mathematics could be recognized in elementary students' activities.

Ways to strengthen the foundation of professional knowledge around the implementation of tasks was a topic that for which numerous scholars offered, as virtually everyone rejected the notion of materials that are "teacher proofed." Kulberg and Montiel et al. discussed how teaching can be improved through the way that teachers understand and approach cases. Stories were used to reach teachers and strengthen their involvement in task activities (Noruzi et al., Dietiker et al.). Joubert $\&$ Mostert and Lee involved teachers as co-designers and partners. Viewing teachers as central to the process of identifying and fostering emergent thinking and supporting discourse (Olsher et al.) was critical to many participants (learning to listen and support discourse and argumentation) There was also an emphasis on teacher community in this process including comparing novice and experienced teachers (Gao \& Zhang) and studying collaborative teacher tasks (Lee et al.).

The final theme emerged around the idea of learning systems, systems in which tasks are embedded but allow students to proceed in personalized ways and at times, include assessments and feedback (Basila, Confrey). Sometimes this resided in Microworlds and dynamic software environments such as a similarity game (Olsher et al.) and for others the learning system actually included the learning systems that permitted a multi-site, multi-theory construction of an e-textbook. (Barquero et al.) with two geographically disparate communities designed an e-book. MathCity Math (Zender \& Ludwig) even described a system that leveraged GPS and permitted mathematics activities to be constructed in real time at different locations around a city.

Overall the TSG 36 showed evidence that the field of task design, analysis and learning environments is continuing to grow and offer new forms of insights.

\section{Tuesday, 26 July 2016, 12.00-13.30, 1st Session}

- Confrey, Jere: Welcome/overview

- Watson, Anne: Parameters for practice and research in task design in mathematics education

- Gravemeijer, Koeno: A personal take on instructional design 
Tuesday 26 July 2016

- Paoletti, Teo; Moore, Kevin C.; Stevens, Irma E.: Task-design principles for covariational reasoning

- Palatnik, Alik: Towards a typology of students' mathematical research projects

- Mok, Ida Ah Chee: Experiencing meaningful school mathematics: rich tasks for inequality

- Dietiker, Leslie; Brakoniecki, Aaron; Miller, Elyssa R.; Richman, Andrew S.: Enacted task design: tasks as written in the classroom

\section{Tuesday 26 July 2016}

- Gao, Xiang; Zhang, Bo: A comparison of novice and experienced teachers' design of a question sequence

- Schäfer, Marc; Linneweber-Lammerskitten, Helmut: Enhancing mathematical curiosity through Vitalmaths video clip tasks

- Lee, Arthur Man Sang: Developing collaborative rich tasks with teachers in Hong Kong classrooms

- Tan, Phei Ling; Kor, Liew Kee; Sam, Prof. Dr. Lim Chap: Applying attribute hierarchy method in task design and item analysis for the topic "time" in primary mathematics

- Udinkaew, Choosak; Saengpun, Jensamut: Designing mathematical tasks for developing mathematical thinking in classroom taught through open approach

- Wilkes II, Charles E.: Sophisticated mathematics: What does it look like for fifth graders

\section{Wednesday 27 July 2016}

- Nunokawa, Kazu: Bridging students' ideas and lessons' goals

- Kulberg, Angelika: Variation within sets of examples

- Barquero, Berta; Papadopoulos, Ioannis; Barajas, Mario; Kynigos, Chronis: Cross-case design in using digital technologies: Two communities of interest designing a c-book unit

\section{Friday 29 July 2016}

- Thiel-Schneider, Alexandra: How does the connection of different perspectives on exponential growth succeed?

- Brady, Corey; Eames, Cheryl; Jung, Hyunyi: Design principles for curricular sequences focused on models and modeling

- Albersmann, Natascha: Construction of mathematical tasks for parents and their children on secondary school level

- Cheng, Jing; An, Shuhua; Bao, Jiangsheng: Cognitive demand of mathematics opening problems exhibited by expert secondary mathematics teachers in Shanghai-China

\section{Friday 29 July 2016}

- Kraemer, Jean Marie; Brocardo, Joana Maria; Mendes, Fatima; Delgado, Catarina: Designing tasks for adaptive/flexible multiplicative reasoning

- Isidro Camac, Lilian Edelmira; Ordoñez Montañez, Candy Clara; Paz Huaman, Gina Patricia: Authentic tasks to assess math competence in learning progress maps

- Kim, Dong-Won; Park, JinHyeong: Building mathematical statements through exemplifying

- Montiel, Gisela; López-Acosta, Luis; Cantoral, Ricardo; Scholz, Olivia: Design-based socioepistemological research 


\section{Friday 29 July 2016}

- Forsythe, Susan Kathleen: Analysis of students' work with a dynamic figure through the lens of Duval

- Olsher, Shai; Shternberg, Beba; Yerushalmy, Michal: Guess who: Addressing meaningful characteristics as means to discover which is the chosen dynamic figure

- Posov, Ilya Aleksandrovich; Mantserov, Dmitry Irikovich: Using free software to implement verification problems with parameters

- Zender, Joerg; Ludwig, Matthias: Mathcitymap (MCM): from paper to smartphone-a new approach of an old concept

Friday 29 July 2016

- Noruzi, Sepideh; Mehrmohammadi, Mahmoud: Teaching mathematics through different genres of stories

- Johnson, Heather Lynn: Designing technology-rich tasks to foster secondary students' covariational reasoning

- Rasila, Antti; Sangwin, Christopher J.: Development of stack assessments to underpin mastery learning

- Joubert, Marie; Mostert, Ingrid: Using 'learning experiences' in South African classrooms: Implications for a teacher toolkit

- Sharma, Bibhya; Kumar, Bijeta; Bali, Akeshnil: Online mathematics diagnostic test and remediation for new entrants in higher education in the pacific region

\section{Saturday 30 July 2016}

- Hoyles, Celia \& Noss, Richard: Mathematics and digital technology: Challenges and examples from design research

- Confrey, Jere: A reflection on the evolving agenda of the TSG 36 on task design, analysis and learning environments

Open Access Except where otherwise noted, this chapter is licensed under a Creative Commons Attribution 4.0 International License. To view a copy of this license, visit http://creativecommons. org/licenses/by/4.0/.

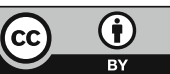

